\title{
Head Movement, Suspended Affixation, and the Turkish Clausal Spine
}

\author{
Kutay Serova*
}

\begin{abstract}
Previous work has shown that Turkish has two structurally different ways of forming predicates with a range of effects for phonological stress, the selection of verbal suffixes, and particle placement (Hankamer 2008; Kelepir 2001; Kornfilt 1996; Zanon 2014). I present evidence drawn from a pilot study of a previously unnoticed difference between these predicate types: In vP-sized or larger coordinated phrases which realize a single sentencefinal predicate, verbal predicates are highly degraded when the person features on the conjuncts' subjects mismatch, while participial predicates are relatively acceptable under the same conditions. Building on Kelepir (2001) \& Zanon (2014)'s work on head-movement in Turkish predicates, I argue that gapping generates these strings from different sized coordinations, and explains the grammatical degradation split observed in the pilot study if we assume a more stringent identity requirement in Turkish gapping than we do for English.
\end{abstract}

Keywords. head movement, suspended affixation, coordination, gapping, ellipsis, agreement, phi features, identity, Turkish

1. Introduction. Turkish predicates belong to two types that differ in phonological and syntactic properties such as stress placement, the presence of the Turkic copula $i$, , the attachment positions of the polar question marker, and the range of possible tense morphology. A line of work has studied subsets of these observations and fleshed out structural differences between two types (Good \& Yu 2005; Hankamer 2008; Kabak \& Vogel 2001; Kahnemuyipour \& Kornfilt 2006; Kamali 2011; Kamali \& Samuels 2008; Kelepir 2001; Kornfilt 1996; Sezer 2002; Zanon 2014). In this paper, I study the interactions of vP-sized or larger coordination, gapping, and the structure of these predicate types.

The target strings have the form (1) and (2). I hereafter call these single-predicate strings because they realize a single sentence-final predicate, while each conjunct seems to be at least vP-sized, based on the existence of separate sets of internal and external agreements.

(1) Ali ceviz, (ve) Veli (de) bal getir-di-Ø.

A. walnut CONJ V. TOP honey bring-PAST-3SG

'Ali (brought) walnuts, (and) Veli brought honey.' [verbal single-pred. string]

(2) Ali ceviz (ve) Veli (de) bal getir-miş-Ø-ti-Ø.

A. walnut CONJ V. TOP honey bring-PFV-COP-PAST-3SG

'Ali (had brought) walnuts, (and) Veli had brought honey.' [participial single-pred. string]

There are several possibilities for the underlying size of the coordination and different possible mechanisms generating these strings. One mechanism possibly at play is gapping, specifically backward gapping, which elides the first conjunct predicate; across-the-board movement is another contender. I argue that gapping is the mechanism deriving both target constructions. I propose that verbal single-predicate strings, like (1), are TP-sized coordinations with gapping T, and participial ones, like (2), are AspP-sized coordinations with gapping of Asp.

I also present pilot study data regarding grammaticality degradation in these constructions conditioned by the syntactic features of conjunct subjects. The pilot data raises two problems for theories of agreement

\footnotetext{
*I thank Boris Harizanov, Jorge Hankamer, the members of the Stanford Syntax-Morphology Circle, and the audiences of Tu+4 and SCULC 2018 for their feedback and support. Special thanks to Vera Gribanova for her never-ending mentorship. Author: Kutay Serova, Stanford University (kserova@stanford.edu).
} 
and gapping. Firstly, the sentence-final predicate in single-predicate strings always agrees with the last conjunct's subject, even when there are other eligible subject DPs in the coordinated structure (Ince 2009). Since the conjunct agreement literature has focused primarily on coordinated nominals, agreement in vPsized or larger coordinations has yet to receive extensive study (Bhatt \& Walkow 2013; Bošković 2009; Koylu 2018; Marušič et al. 2007). I do not tackle this problem here, focusing on the second one instead.

The second problem is that single-predicate strings show grammaticality degradation conditioned by the person features of each conjunct's subject. If these features on the conjunct subjects mismatch, verbal single-predicate strings are highly degraded, while participial ones are acceptable. To my knowledge, this is a new observation about gapping and suspended affixation in vP-sized or larger coordinations. This degradation split not only adds a new behavioral difference between verbal and participial structures, but also allows further probing of their structure. To tackle this problem, I study the underlying structures of the target constructions using Kelepir (2001), Kornfilt (1996), \& Zanon (2014)'s analyses on Turkish predicates, and develop a preliminary analysis that explains these effects if we assume more stringent constraints on Turkish gapping than English gapping.

My proposal accounts for the degradation split in the pilot data between verbal vs. participial singlepredicate strings under person feature mismatches between the conjunct subjects. However, it loses some more fine-grained differences regarding a hierarchy of acceptability conditioned by specific combinations of subjects. Since these subtler patterns are not very clear in the pilot data, I am currently conducting a controlled judgment task experiment to fill this gap and follow up these findings with more fine-grained and robust empirical data.

I extend the analyses of Turkish predicate structure developed in Kornfilt (1996), Kelepir (2001), and Zanon (2014) to the target construction. ${ }^{1}$ Section $\$ 2$ provides background on the Turkish predicate types and evidence motivating their structural analyses. Section $\S 3$ discusses the predictions of previous work for different sized coordinations in the underlying structure of the target constructions, and presents evidence of a degradation pattern from two pilot studies. Section $\S 4$ presents an analysis involving a more stringent identity requirement for gapping in Turkish, and demonstrates how this proposal addresses the degradation split found in the pilot data.

\section{Background.}

2.1. StRUCtURAL PREDiCATE TYPeS. Turkish predicates belong to two groups based on their syntactic and phonological behavior. These types are not sets of lexical items, but two different syntactic structures involving predicates, tense, and agreement.

The first category consists of verbs inflected with the simple past tense - $d I$, labeled verbal predicates ${ }^{2}$. These constructions exhibit standard word-final stress on the inflected verb, never realize the Turkish copula $i$-, and don't allow the polar question marker $-m I$ to attach between the verb and tense-agreement morphology (Kahnemuyipour \& Kornfilt 2006; Kelepir 2001; Kornfilt 1996; Zanon 2014). This group also does not allow suspended affixation of tense-agreement suffixes, i.e. one set of tense-agreement suffixes cannot scope over a coordination of predicates, (3).

(3) *Deniz-e git, güneş-te kızar, ve eğlen-di-k. sea-DAT go sun-LOC roast CONJ enjoy.REFL-PAST-1PL

intended: 'We went to the sea, got roasted in the sun, and had fun.' (adap. Hankamer (2008))

\footnotetext{
${ }^{1}$ I assume the structure of the predicates and the different termination points of the head-movement in the two predicate types. Zanon (2014)'s reanalysis of TP as ModP is not crucial for this proposal.

${ }^{2}$ Kornfilt (1996) includes conditional with -sA in this group. I omit conditionals as they introduce new confounds.
} 
The other group, copular predicates, is a structure involving predicative nouns, adjectives, and verbs with participial affixes. The predicates in this group share external properties such as expressing phonological stress in a smaller domain, being compatible with the full range of tense morphology (present, past, and evidential), realizing the copula, and allowing the polar question marker to surface between the predicate and tense-agreement morphology (Kahnemuyipour \& Kornfilt 2006; Kelepir 2001; Kornfilt 1996; Zanon 2014). This paper focuses on only the participial predicates from this group, as the rest have identical external distribution and don't interact with head-movement due to their internal structure. Suspended affixation of tense-agreement morphology is grammatical with participial predicates, as in (4) (Hankamer 2008; Kelepir 2001).

(4) Deniz-e gid-ecek, güneş-te kızar-acak, ve eğlen-ecek- $\emptyset$-ti-k.

SEa-DAT go-Fut sun-LOC roast-FUT CONJ enjoy.REFL-FUT-COP-PAST-1PL

'We were going to go to the sea, get roasted in the sun, and have fun.' (adap. Hankamer (2008))

2.2. HeAD-MOVEMENT IN TURKISH PREDICATES. Kornfilt (1996) suggests head-movement as a mechanism to cover the range of morphosyntactic and phonological effects, and Kelepir (2001) \& Zanon (2014) develop a formal head-movement analysis. According to this model, verbal predicates have obligatory roll-up head-movement from $\mathrm{V}$ up to $\mathrm{T}$, as in (5). In contrast, participial predicates head-move to a lower projection, terminating at Asp, crucially not reaching $\mathrm{T}$, as in (6).

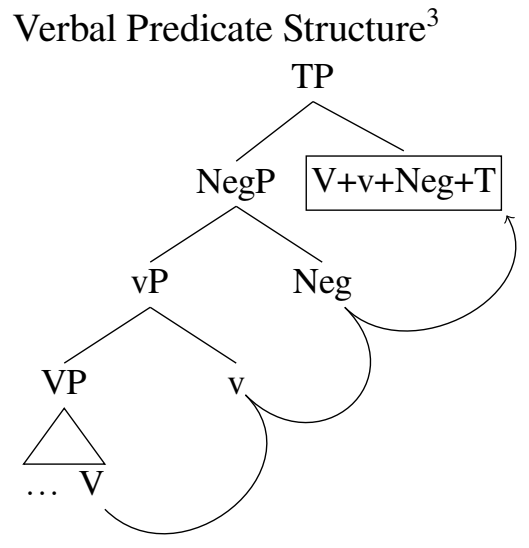

(6)

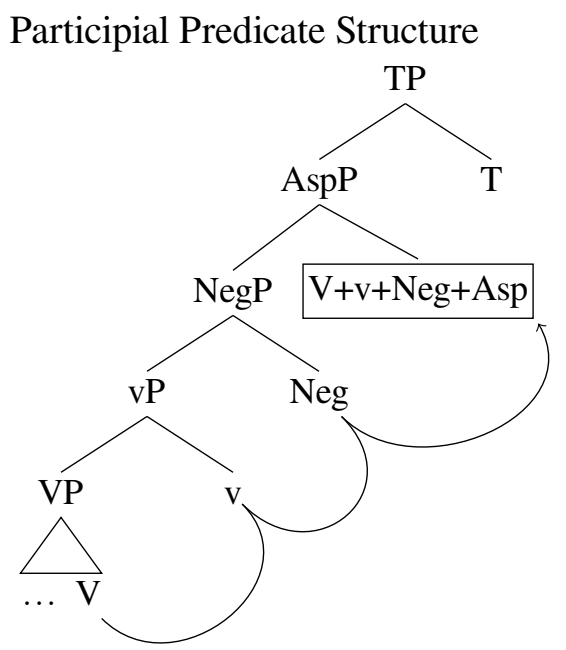

The complex heads created by the head-movement chains in (5) and (6) generate different morphosyntactic domains in verbal vs. participial predicate constructions. In verbal predicates, the fully inflected verb is a complex head. Participial predicates have a smaller complex head excluding T. ${ }^{4}$ This asymmetry generates different morphosyntactic domains for PF-interface phenomena such as stress assignment, and constrains the syntactic structures available due to the constraints on syntactic movement. The evidence motivating this theory is presented below in sections $§ 2.3-\S 2.6$.

\footnotetext{
${ }^{3}$ Asp is never realized overtly within verbal predicates, so I assume no Asp head in their structure, with T selecting for a NegP or vP. Alternatively, there could be a null Asp.

${ }^{4}$ I assume agreement to be post-syntactic realization of features on T. Other formulations are compatible as long as tense and agreement are trapped inside a complex head in verbal predicates and not in participial ones.
} 
2.3. Phonological Stress. Turkish stresses the final syllable in the standard case, when irregular lexical stress and pre-stressing elements don't override the standard stress mechanism and stress non-final syllables inside the phonological word (Kabak \& Vogel 2001). Verbal and participial predicates differ in standard phonological stress placement, regardless of syllable count or purely phonological criteria (Kabak \& Vogel 2001; Kamali \& Samuels 2008). Verbal predicates stress the last syllable of the fully-inflected verb, (7), while participial predicates stress the last syllable of the predicate before tense and agreement suffixes, (8). The two predicate types have different stress assignment domains, as schematized below.

(7) [verbal predicate stress]

$$
\begin{aligned}
\text { a. } & *[\text { yakalá }]_{\mathrm{PrWd}}-\mathrm{d}_{1}-\mathrm{n} \mathbf{} \\
& \text { catch }-\mathrm{PAST}-2 \mathrm{PL} \\
\text { b. } & *[\text { yakala-dí }]_{\mathrm{PrWd}}-\mathrm{n} \mathbf{} \\
& \text { catch-PAST }-2 \mathrm{PL} \\
\text { c. } \quad[\text { yakala-d1-níz }]_{\mathrm{PrWd}} & \\
& \text { catch-PAST-2PL } \\
& \text { 'You (pl.) caught it.' }
\end{aligned}
$$

(8) [participial predicate stress]

$$
\begin{aligned}
\text { a. } & *[\text { Çalíş }]_{\text {PrWd }} \text {-tır-acak- } \varnothing \text {-tı-m. } \\
& \text { work -CAUS-FUT-COP-PAST-1sG } \\
\text { b. } & *[\text { Çalış-tír }]_{\text {PrWd }} \text {-acak- } \varnothing \text {-tı-m. } \\
& \text { work-CAUS -FUT-COP-PAST-1sG } \\
\text { c. } & {[\text { Çalış-tır-acák }]_{\text {PrWd }}-\varnothing \text {-tı-m. } } \\
& \text { work-CAUS-FUT -COP-PAST-1sG } \\
& \text { I was going to make him/her work.' }
\end{aligned}
$$

The verbs in (7) \& (8) are all assigned standard final-stress as they lack irregular lexical stress and pre-stressing elements such as verbal negation. The verbal predicate has a single stress assignment domain, while the participial predicate has two: one larger prosodic word including tense and agreement suffixes, and a smaller one excluding tense and agreement morphology. These stress patterns follow regular finalsyllable stress assignment in the smaller of these domains (Kahnemuyipour \& Kornfilt 2006). This is predicted by the head-movement proposal, as complex heads map to prosodic words in PF, establishing a correspondence between stress assignment boundaries and complex heads.

2.4. The POSITION OF THE COPULA. The Turkish copula has two phonological realizations: cliticized to the predicate, (9-b) \& (10-b), and phonologically separate, (9-a) \& (10-a).

(9) [V-stem participial pred. with copula]
a. Hasta $\mathbf{i}-\mathrm{di}-\varnothing$.
sick COP-PAST-3SG
b. Hasta-y-d1- $\varnothing$.
sick-COP-PAST-3SG
'S/he was sick.'

(10) [C-stem participial pred. with copula]
a. Doktor i-di- $\varnothing$.
doctor COP-PAST-3SG
b. Doktor- $\varnothing-\mathrm{du}-\varnothing$.
doctor-COP-PAST-3SG
'S/he was a doctor.'

When separate, the copula behaves as a separate phonological word, not extending vowel harmony, $(9-a) \&(10-a)$. When it is a clitic, the copula is phonologically leans on the predicate in PF, and the copula is pronounced as a glide - $y$ - post-vocally, and phonologically null following consonants, as in (9-b) \& (10-b) (Kornfilt 1996). Crucially, the copula in never realized in verbal predicate constructions. Therefore verbal predicates can never be broken into two phonological words by a copula, (11) \& (12).

(11) [V-stem verbal predic. with copula]

a. *Yakala i-di-m.
catch COP-PAST-1sG

\author{
b. *Yakalá-y-di-m. \\ catch-COP-PAST-1SG \\ intended: 'I caught it.'
}


[C-stem verbal pred. with copula]

a. *Yáz i-di-m. write COP-PAST-1sG b. *Yáz-Ø-d1-m.

write-COP-PAST-1sG

intended: 'I wrote.'

The attachment position of the copula indicates the presence of a smaller morphosyntactic word in participial predicates. Verbal predicates lack the morphosyntactic boundary associated with the copula, and thus do not exhibit optionally separable tense and agreement morphology.

2.5. THE POSITION OF THE POLAR QUESTION MARKER. The polar question marker - $m I$ attaches to the right edge of phrases carrying focus and sentential stress in biased and unbiased polar questions (Kamali 2011). Under certain types of focus and in the lack of any focused elements, the polar question marker attaches to the predicate in distinct positions for verbal and participial predicates.

In verbal predicates, it follows tense-agreement suffixes, to the right edge of the fully inflected verb, (13-a), and cannot attach to smaller units, such as (13-b). In participial predicates, the marker attaches between the right edge of the predicate and tense-agreement morphology, i.e. to the morphosyntactic domain that marks the boundaries of the stress assignment domain discussed in $\S 2.3$, as can be seen in (14-a) vs. (14-b).
a. $\quad[$ Yakala-di-n] $=\mathbf{m i}$ ?
catch-PAST-2sG $=\mathbf{Q}$
'Did you catch it?'
b. $*[$ Yakala $]=$ mi-d1-n?
catch $=\mathrm{Q}-\mathrm{PAST}-2 \mathrm{SG}$
int'd: 'Did you catch it?'
a. $\quad$ [Yakala-yacak $]=\mathbf{m i}-\varnothing-\varnothing$-sınız?
catch-FUT $\quad=\mathbf{Q}$-COP-PRES-2PL
'Are you all going to catch it?'
b. $*[$ Yakala $]=$ mı-yacak- $\varnothing-\varnothing-$-sinız?
catch $=\mathbf{Q}$-FUT-COP-PAST-2PL
int'd: 'Are you all going to catch it?'

Elsewhere within a sentence, the polar question marker attaches to phrases regardless of category, but its distribution in the predicate domain is restricted. Given the versatility of $-m I$ in attaching to different constituents for realizing subtle focus and discourse phenomena, the distributional restriction in the predicate domain is unexpected. Head-movement explains this restriction by creating complex heads: Verbal forms have a complex head including $\mathrm{T}$, which the domain for $-m I$ attachment, while participial forms have a complex head that includes Asp but not $\mathrm{T}$, marking a smaller domain for $-m I$ attachment.

2.6. Suspended AfFixAtion. Suspended affixation involves a head, realized as an affix, that scopes over a conjunction which in its complement position (Hankamer 2008). Turkish allows optional suspended affixation in some nominals, (15), as well as predicate structures, (16).
a. kedi-ler ve köpek-ler cat-PL CONJ dog-PL
'cats and dogs'
b. kedi ve köpek-ler cat CONJ dog-PL 'cats and dogs'

(16) [Köy-ün en zengin adam-1] ve [bölge-nin en ünlü hırsız-1] -y-dı-m. village-GEN most rich man-POss CONJ area-GEN most famous thief-POSS -COP-PAST-1sG 'I was the richest man in the village, and (I was) the most famous thief in the area.'

(adapt. Hankamer (2008))

Participial predicates allow suspended affixation of the copula and tense-agreement suffixes, (16) \& (17), while verbal predicates do not, (18). 
(17) Deniz-e gid-ecek, güneş-te kızar-acak, ve eğlen-ecek-Ø-ti-k.

SEa-DAT gO-FUT sun-LOC roast-FUT CONJ enjoy.REFL-FUT-COP-PAST-1PL

'We were going to go to the sea, get roasted in the sun, and have fun.' (adapt. Hankamer (2008))

(18) *Deniz-e git, güneş-te kızar, ve eğlen-di-k.

Sea-DAT go sun-LOC roast CONJ enjoy.REFL-PAST-1PL

intended: 'We went to the sea, got roasted in the sun, and had fun.' (adapt. Hankamer (2008))

Kelepir (2001) \& Zanon (2014) explain the unavailability of suspending tense and agreement in verbal predicate constructions with the Coordinate Structure Constraint (CSC). According to the CSC, an element cannot be asymmetrically extracted from a coordination (Baker 1985; Baker 1988; Ross 1967). So, if the head-movement chain in verbal predicates proceeds to T, structures like (19) incur a violation, making suspended affixation in verbal predicates impossible.

CSC Violation in verbal predicate suspended affixation

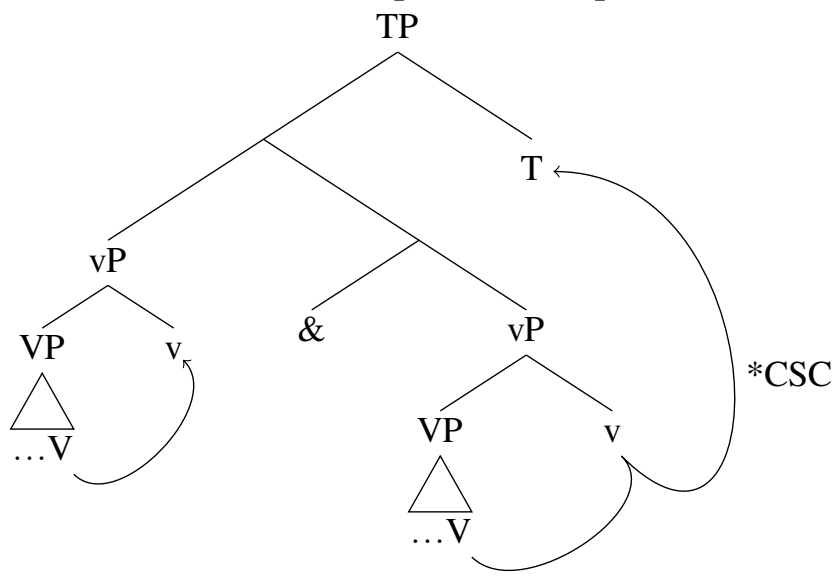

And indeed, the would-be result (20) is ungrammatical.

(20) *Biz dün klyafet al, ve bugün meyve sebze al-dı-k.

1PL yesterday clothes buy CoNJ today fruits_and_veggies buy-PAST-1PL

'We bought clothes yesterday and bought fruits and vegetables today.'

Of course, the unacceptability of (20) could also result from morphological requirements, since bare verb roots do not fulfill the requirements for minimal words in Turkish (Kabak 2007). Regardless, if (19) is the underlying structure for (20), it also incurs a syntactic CSC violation, deriving the unavailability of suspended affixation in verbal predicate constructions.

2.7. Summary. The morphosyntactic domains for phonological stress, copula position (when present), polar question marker attachment, and the suspended affixation have different sizes in verbal and participial predicates. Kelepir (2001) \& Zanon (2014)'s head-movement analysis accounts for these observations by having roll-up head-movement up to $\mathrm{T}$ in verbal predicates, and to Asp but crucially below $\mathrm{T}$ in participial predicates, creating complex heads that match these morphosyntactic domains, and explain the ungrammaticality of suspended affixation of tense-agreement suffixes in verbal predicates.

3. Coordination and Gapping. Kelepir (2001) \& Zanon (2014) focus on suspended affixation and the morphosyntactic behavior of Turkish predicates. Thus, they do not explore predictions of their proposal 
for coordinated structures; however, their analysis allows for different sized coordinations, so there are several possibilities for the underlying structures of single-predicate strings, with different predictions: two different sizes of coordination (vP-sized vs. TP-sized), and two different mechanism at work (acrossthe-board movement vs. gapping).

In section $\S 4$, I argue that the structures of verbal and participial single-predicate strings involve gapping instead of across-the-board movement; however, before I present the motivating pilot data, I would like to sketch the possible underlying structures for verbal vs. participial single-predicate strings ((21) and (22)) that follow from previous work Turkish predicate structure.

(21) Ali ceviz, (ve) Veli (de) bal getir-di-Ø.

A. walnut CONJ V. TOP honey bring-PAST-3SG

'Ali (brought) walnuts, and Veli brought honey.'

[verbal predicate]

(22) Ali ceviz (ve) Veli (de) bal getir-miş-Ø-ti-Ø.

A. walnut CONJ V. TOP honey bring-PFV-COP-PAST-3SG

'Ali (had brought) walnuts, and Veli had brought honey.'

[participial predicate]

The different heights of the head-movement chains in verbal and participial predicates constrain the array of potential structures for verbal vs. participial single-predicate strings.

3.1. Verbal SingLE-PREDICATE STRINGS. (21) could potentially be derived from precisely the vP-sized coordination that disallows suspended affixation due to the CSC. The structure in (23) would derive (21) by across-the-board (ATB) head-movement to T, which does not violate the CSC due to symmetric extraction, and it doesn't strand a morphologically incomplete verb. The hypothetical result of (23) is (24), where the underscored regions mark the gaps the verbs were extracted from.

(23) Verbal single-pred. string, $\mathrm{vP}$-sized coordination

Across-the-board head-movement to T

Does not yield pilot facts

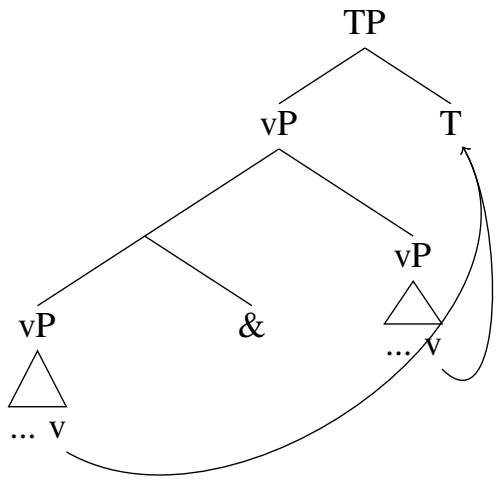

(24) [Biz dün kiyafet _ ], ve [bugün meyve sebze _ _ ] al-dı-k.

1PL yesterday clothes CONJ today fruits_and_veggies buy-PAST-1PL

'We bought clothes yesterday and bought fruits and vegetables today.'

Due to obligatory head-movement up to T, coordinations smaller than TP require extraction out of the coordination (Kelepir 2001; Zanon 2014). If one assumes a vP-sized coordination like (23), the only movement operation that avoids CSC violations is across-the-board movement. However, there are inde- 
pendent arguments against such an analysis. İnce (2009) presents syntactic and scopal arguments against ATB head-movement in such strings. I do not directly engage with these arguments due to space constraints and the boundaries of the pilot data; but I add another argument against this analysis in section §: ATB head-movement does not yield the degradation patterns found in the pilot data.

The alternative analysis that I argue for involves gapping. If we assume a TP-sized or larger coordination, each conjunct houses a separate $\mathrm{T}$ that realizes an inflected predicate. Since single-predicate strings realize only the final predicate, gapping is active in these constructions, marking the $\mathrm{T}$ head for non-pronunciation at $\mathrm{PF}$, as shown in (25).

(25) Verbal target, TP-coord., gapping of T

Yields pilot facts

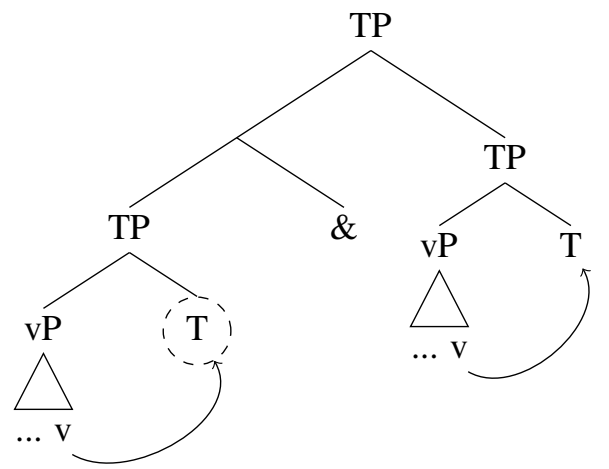

3.2. PARTICIPIAL SINGLE-PREDICATE STRINGS. In contrast to verbal predicates, head-movement in participial predicates does not reach T, so coordinations both below and above T avoid CSC violation by not requiring extraction.One possibility is (26), with an AspP-sized coordination below T, and gapping of the complex head housing a participle at Asp. Conversely, if the coordination is TP-sized or larger, as in (27), both Asp and T need to be gapped to generate the single-predicate string.

(26)

Participial target, AspP-coord. gapping of Asp

Yields pilot facts

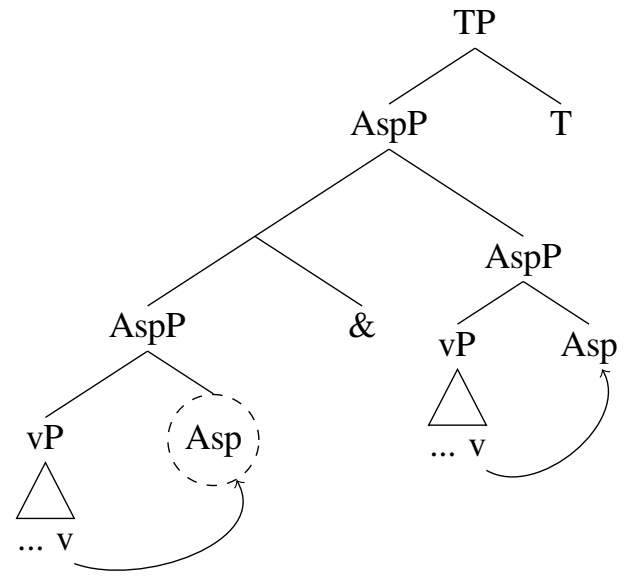

(27) Participial target, TP-coord. gapping of Asp \& T Does not yield pilot facts

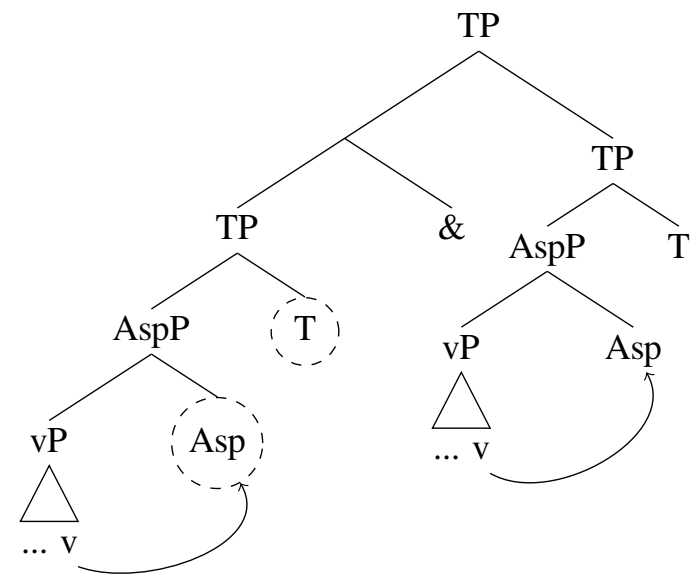

3.3. Pilot Study eVidenCE: AgReEment with COnJunct SubjeCts. While verbal and participial singlepredicate strings look surface-similar, they exhibit different behavior in the target constructions, providing 
a tool to narrow down the possible underlying structures for the target constructions. I followed up a personal observation about colloquial usage with a pilot study to examine whether there is a systematic degradation pattern in single-predicate strings conditioned by the features of conjunct subjects.

Single-predicate strings are acceptable when the subjects of the conjuncts match in person features, as can be seen in the previously discussed examples (1), (2), (21), (22), and (24), as well as some others below: (28) for an example with nouns, (29) for one with non-co-referential pronouns. ${ }^{5}$

Anneanemler Ankara'ya, halamlar (da) Bursa'ya git-ti-ler.

grandmother-1sG-PL A.-DAT CONJ aunt-1sG-PL TOP B.-DAT go-PAST-3PL

'My grandmother and her family went to Ankara, and my aunt and her family (went) to Bursa.'

(29) Onlar $_{i}$ Ankara'ya, $\quad \operatorname{onlar}_{j}$ (da) Bursa'ya git-ti-ler.

3PL A.-DAT CONJ 3PL TOP B.-DAT go-PAST-3PL

'They ${ }_{i}$ went to Ankara, and they ${ }_{j}$ (went) to Bursa.'

However, the pilot results show that verbal target constructions are quite degraded when the conjunct subjects mismatch in person features. Participial single-predicate strings are slightly degraded, but relatively acceptable under the same conditions.

I conducted two pilot studies looking at cases of person feature mismatch between conjunct subjects: one studying verbal single-predicate strings, and a follow-up study with both verbal and participial singlepredicate strings. Firstly, they replicate İnce (2009)'s observation that single-predicate strings require verbal agreement with the last conjunct's subject, even when there are other eligible subject DPs in the structure. This fact of Turkish is an enigmatic behavior that raises questions regarding the exact theoretical implementations of agreement. However, most importantly for this paper, the data reveals an interesting degradation pattern with differences between verbal and participial predicates and consequences for gapping in Turkish.

Pilot Study \#1. This preliminary pilot study focused on verbal predicates, following personal observations about degradation conditioned by conjunct subjects. This was an acceptability judgment task using a 15 Likert scale with 21 native Turkish speakers, manipulating (i) the person and number features of the conjunct subjects, (ii) whether verbal agreement was controlled by the last (closest) or the first (farthest) conjunct subject, and (iii) whether 3rd person plural marker was overt or covert. ${ }^{6}$ The stimuli were of the form (30) and (31), with replacement of the subject pronouns and verbal agreement suffixes. The verb and arguments were the same across all stimuli.

(30) *Ben çay ve sen kahve iç-ti-m.

1sG tea CONJ 2sG coffee drink-PAST-1sG intended: 'I drank coffee and you drank tea.'

[agr. with first conj. subj.]

(31) ?Ben çay ve sen kahve iç-ti-n.

1SG tea CONJ 2SG coffee drink-PAST-2SG intended: 'I drank coffee and you drank tea.'

[agr. with last conj. subj.]

Firstly, the results replicated the observation that agreement with the first conjunct's subject, as in (30) is ungrammatical across-the-paradigm (İnce 2009), getting the lowest possible rating, 1 out of 5, in vir-

\footnotetext{
${ }^{5}$ Co-referential pronouns are frequently dropped, as Turkish is strongly pro-drop language.

${ }^{6}$ There is variation in the $3 \mathrm{pl}$ verbal agreement morphology in current day Turkish. The results did not show any specific pattern.
} 
tually all stimuli, with a mean score of $1.6 / 5$. In the other condition - agreement with last conjunct's subject - some subject combinations were more acceptable than others, hinting at a possible hierarchy of grammaticality conditioned by the order and combination of subjects with different person features. The scores for this condition are reported in (32).

\begin{tabular}{llrll}
\multicolumn{2}{l}{ Pilot Study \#1: Verbal single-predicate strings } \\
\hline first conj person & last conj person & avg score. & stdev & num judgments \\
\hline 3 & 1 & 4.29 & 2.34 & 84 \\
2 & 1 & 3.85 & 2.14 & 84 \\
3 & 2 & 3.52 & 2.25 & 84 \\
1 & 2 & 3.49 & 2.17 & 84 \\
2 & 3 & 3.40 & 2.06 & 126 \\
1 & 3 & 3.15 & 2.14 & 126 \\
\hline
\end{tabular}

Note that scores are concentrated in the mid-range of the 1-5 scale, and have large standard variations. The short range of the Likert scale, repetitive stimuli template, and small sample size represent disadvantages of the preliminary study. However, the results still show the a gradation of acceptability both within and between the two predicate types. The mean scores, as well as free-form native speaker comments, suggest that the subject combinations have an effect on grammaticality: $3^{\text {rd }}$ person $\& 1^{\text {st }}$ person subject order is relatively better, while $1^{\text {st }} \& 3^{\text {rd }}$ person order is comparatively worse. While this data is a precursor to further study, it justifies a question worth exploring: Is there an effect between the features of the conjunct subjects and grammaticality?

Pilot Study \#2. Based on the first pilot, I conducted a variation on the same study which compared verbal and participial predicates. This study used a larger 1-7 Likert scale, and was conducted with 8 native Turkish speakers. The participial stimuli used the perfective suffix $-m I s$, and the stimuli were based on the templates in (33) and (34) below, substituting the subjects and verbal agreement. All other material was held constant across stimuli.

(33)?*Ben dün akşam çay, Aliler o sirada kahve iç-ti-Ø.

1SG yesterday_evening tea CONJ Ali_and_others that_time coffe drink-PAST-3PL

'I drank tea yesterday evening, and Ali and the others drank coffee.' [verbal pred.]

(34) ?Ben dün akşam çay, Aliler o sırada kahve içmiş-ti-Ø.

1SG yesterday_evening tea CONJ Ali_and_others that_time coffe drink-PFV-COP-PAST-3PL

'I drank tea yesterday evening, and Ali and the others drank coffee.' [participial pred.]

As expected, agreement with the first conjunct's subject was ungrammatical, with mean ratings of 1.40/7 and 1.50/7 for verbal and participial predicates. Mean scores for agreement with the last conjunct's subject were in the $4 / 7$ to $5 / 7$ mid-range for both predicate types, showing that single-predicate strings are not slightly dispreffered to alternatives. However, the mean ratings for participial predicates were higher than verbal predicates in all combinations, presenting a clear split, as presented in (35) below.

(35) Pilot Study \#2: Verbal vs. participial single-predicate strings 


\begin{tabular}{lllrll}
\hline first conj person & last conj person & predicate type & avg score & stdev & num judgments \\
\hline 1 & 2 & participial & 5.14 & 1.60 & 28 \\
2 & 1 & participial & 4.75 & 1.60 & 28 \\
1 & 3 & participial & 4.75 & 1.67 & 28 \\
3 & 2 & participial & 4.57 & 2.12 & 28 \\
3 & 1 & participial & 4.46 & 1.91 & 28 \\
2 & 3 & participial & 4.39 & 1.81 & 28 \\
\hline 1 & 2 & verbal & 4.46 & 1.88 & 28 \\
3 & 1 & verbal & 4.46 & 1.95 & 28 \\
2 & 1 & verbal & 4.43 & 1.87 & 28 \\
3 & 2 & verbal & 4.32 & 2.00 & 28 \\
2 & 3 & verbal & 3.96 & 1.79 & 28 \\
1 & 3 & verbal & 3.86 & 2.16 & 28 \\
\hline
\end{tabular}

There is gradience both within and between verbal and participial predicates conditioned by person features of conjunct subjects. The small sample size is a limiting factor, however, speaker judgments and raw mean ratings show a gradience between the predicate types.

Until more robust and finer-grained empirical data is available, I interpret this data as: (i) Agreement with the first conjunct's subject is ungrammatical. (ii) Single-predicate strings are degraded when the person features of the conjunct subjects mismatch. (iii) Participial predicates are more acceptable compared to verbal predicates in single-predicate strings with person feature mismatches.

4. Discussion. The grammaticality split between verbal and participial single-predicate strings under feature mismatches constrains the set of possible analyses. The analysis has to capture two facts about the pilot data: (i) Both verbal and participial target constructions are grammatical when subjects match in person features, and (ii) verbal target constructions are ungrammatical while participial ones are grammatical when the person features of the conjunct subjects mismatch. I argue that gapping is the mechanism building single-predicate strings, and we need to assume a stricter identity requirement for Turkish gapping than English gapping to cover these effects. The structures that yield the pilot patterns are: TP-coordination with gapping of $\mathrm{T}$ for verbal targets, and AspP coordination with gapping of Asp for participial singlepredicate ones.

4.1. NOT ACROSS-THE-BOARD HEAD-MOVEMENT. The across-the-board head-movement account in section $\$ 3$ does not yield the observed degradation effects. If across-the-board head-movement is involved in building verbal target constructions, the coordination must be below a single $\mathrm{T}$ head, shown in (36).

(36) Verbal target, vP-coord., ATB head-movement to T

Does not yield pilot facts

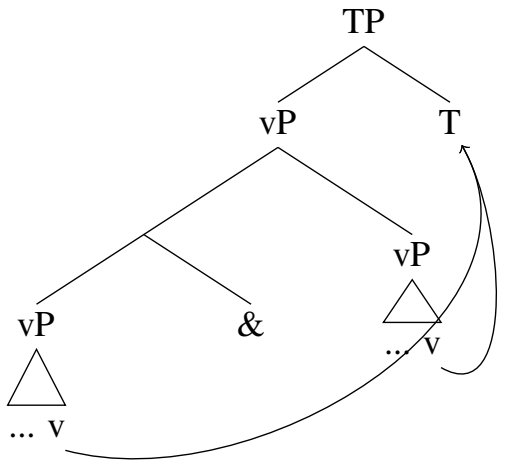


Since there is only one T head in this structure, only one AgreE relation is established. T AgREes with a single DP, and is agnostic to the features of other DPs. Thus, the subjects are allowed to mismatch in features, and this model overgenerates.

While it is possible that both DPs in a coordinated phrase below T count as equidistant by syntactic metrics (embeddedness, etc), how AgreE would handle such a structure, and why Turkish predicates require agreement with the last conjunct subject is still unclear.

On another note, ATB movement cannot provide an analysis for participial target constructions because participial head-movement terminates below $\mathrm{T}$ without extraction from a conjunction. So, gapping has to be active in at least participial target-constructions, as the first conjunct predicate has to marked for non-pronunciation.

4.2. GAPPING YIELDS THE PILOT PATTERN. Both of the structures motivated for participial single-predicate strings by previous work (section §3) involve gapping. The alternative to the ATB-analysis for verbal predicates also requires gapping, so I will show how gapping structures can yield the degradation effects if we adopt a stricter identity requirement for gapping in Turkish, compared to English.

Gapping is a type of ellipsis that targets individual (verbal) lexical items, which I take to be syntactic heads. As with other types of ellipsis, some conditions have to be met for the elision of material. Gapping requires identity of, minimally, the root of a predicate with an antecedent. So, gapping is licensed if a predicate has an antecedent with a matching verb stem, (37), and is ungrammatical otherwise, (38) (Johnson 2006).

(37) a. John likes pasta and Jill (likes) lasagna.

b. I like pasta and Jill (likes) lasagna.

(38) a. John likes lasagna, and Will *(hates) pasta.

b. John ate lasagna, and Will *(made) pasta.

Notice that English gapping even allows agreement morphology to mismatch with the antecedent in (37) as long as the verb stems do. In contrast, the pilot data shows that Turkish does not allow the same range of morphological mismatch. Thus, we can rehash the pilot data observations in morphological terms:

(39) Turkish verbal single-predicate strings are degraded when the un-pronounced predicates have differing agreement morphology with the antecedent.

To unpack, verbal single-predicate strings, such as (40), would involve gapping of a predicate (strikedthrough) that has an antecedent with differing agreement morphology (underlined).

(40) *Ben çay iç-ti-m ve o (da) kahve iç-ti-

1sG tea drink-PAST-1sG CONJ 2SG TOP coffee drink-PAST-3SG

intended: 'I (drank) coffee, and s/he drank tea.'

Indeed, (40) is ungrammatical according to the pilot data. The two predicates differ in agreement suffixes, which are realizations of different $\phi$-features on each conjunct's T head. The syntactic difference between the two predicates is $\phi$-features on T, which are inherited from the conjunct subjects via AgreE. The alternative to the ATB analysis, (41), makes sense of the degradation effect with reference to these features on $\mathrm{T}$.

(41) Verbal target, TP-coord., gapping of T

Yields pilot facts 


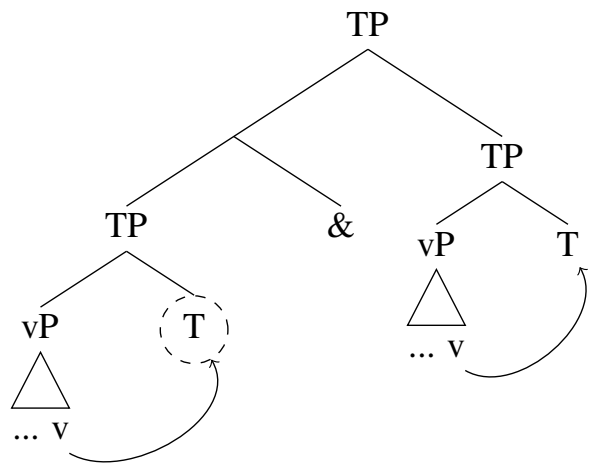

As this structure involves gapping of a predicate, a kind of identity is required for licensing gapping. However, gapping of the first conjunct predicate - a complex head at $\mathrm{T}$ - is ungrammatical when the conjunct subjects, and, consequently, T heads mismatch in $\phi$-features. As the identity requirement for gapping is sensitive to the identity of lexical items, starting with verb stem, in English predicates, I propose that this stricter behavior in Turkish gapping could be explained by a more sensitive identity requirement:

(42) Identity in Turkish Gapping: A head must have an eligible antecedent that matches in both the identity of the lexical item and the syntactic features housed on the head to license gapping.

(42) requires that verbal predicates match with their antecedent in all heads $(\mathrm{V}, \mathrm{v}, \mathrm{T})$ in syntactic features, including $\phi$-features, yielding the degradation effect found in verbal single-predicate strings. Since the predicate in verbal target-constructions is a complex head including the verb root and T, gapping of such predicates is only licensed when the all heads in the predicate matches the antecedent predicate (last conjunct) in lexical items and $\phi$-features. Under -mismatch of subject features, the T heads in the antecedent and ellipsis site do not match in $\phi$-features, not licensing gapping.

This formulation of identity is also compatible with the participial single-predicate strings patterns. One of the structures motivated by previous work, (43) yields the lack of ungrammaticality under featuremismatch. The alternative, (44) does not yield the split in degradation between the predicate types, and thus the underlying structures is the former.

Participial target, AspP-coord. gapping of Asp

Yields pilot facts

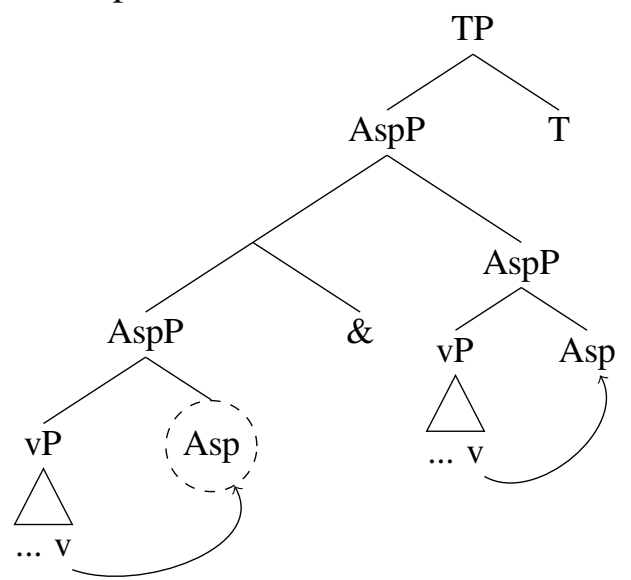

(44) Participial target, TP-coord. gapping of Asp\&T Does not yield pilot facts

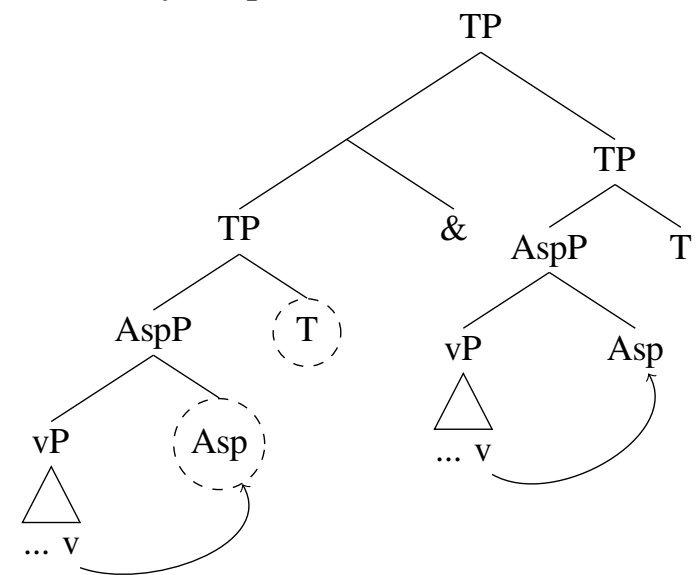


I propose that (43) is the structure of participial single-predicate strings: an AspP-sized coordination below T, with gapping of the first complex Asp head, which houses the heads comprising the participial predicate. Descriptively, this structure involves gapping of participles without any tense-agreement suffixes, because the conjuncts do not have T. Since participial predicates are complex heads which do not include T, the gapped heads (V, v, Asp) do not house any $\phi$-features that would require identity with the antecedent, or be realized with agreement morphology. So, any featural mismatch between conjunct subjects does not block the licensing of gapping, yielding the availability of mismatch in the conjunct subject features of participial single-predicate strings.

The alternative analysis, (44), cannot be the underlying structure of participial single-predicate strings since it doesn't yield the pilot facts. The unpronounced material in this structure is a complex Asp head housing the predicate and T. Since a T head is inside the ellipsis site, the gapped T must match antecedent's T fully, including $\phi$-features. Thus, this structure undergenerates, not generating participial single-predicate strings with feature-mismatching subjects, which are acceptable according to the pilot data.

In summary, we can make sense of the split in verbal vs. participial single-predicate degradation if we assume a more stringent identity requirement in Turkish. Descriptively, the target strings show degradation when the gapped material houses agreement morphology, which is a realization of $\phi$-features on T. So, verbal target-constructions house TP-sized coordinations, while participial ones have AspP sized coordinations in the complement $\mathrm{T}$, and the gapping of different heads yields the split in degradation.

5. Conclusion. I have presented empirical evidence from a pilot study for a new degradation pattern at the intersection of vP-sized or larger coordinations, predicate-internal head-movement, and gapping in Turkish. Building on previous analyses of predicate structure, I argued that gapping is the mechanism generating the target constructions instead of across-the-board head-movement, since gapping can explain the split in degradation through a sensitivity to $\phi$-features in licensing gapping, while across-the-board movement cannot yield the pilot patterns.

I argued that Turkish gapping doesn't allow mismatch in agreement morphology between the antecedent and gapped predicate, unlike English. So, I proposed that Turkish gapping is licensed by a stricter identity criterion requiring identity of both the lexical items and the syntactic features housed on those heads: crucially $\phi$-features on $\mathrm{T}$.

While this theory accounts for the degradation split between verbal and participial single-predicate strings conditioned the features of conjunct subjects, it does not account for the gradation observed within predicate types. I am conducting an acceptability judgement study to generate more fine-grained data with wider coverage. Further study might uncover a more nuanced paradigm or hierarchy than presented here. This study hopes to serve as an indicator for possible interactions between subject features, coordination, and gapping; and generate further research at this intersection.

On another note, while I do not flesh out the theoretical implementation of the strict identity requirement, it is possible that the mechanism responsible for marking heads for non-pronunciation is a postsyntactic process that is sensitive which structure-building processes generate the feature bundles output by the Syntax (head-movement, Agree, etc). The difference between English and Turkish gapping might be due to head-movement generating different boundaries for post-syntactic processes.

\section{References}

Baker, Mark. 1985. The Mirror Principle and Morphosyntactic Explanation. Linguistic Inquiry 16(3). 373-415. URL http://www.jstor.org/stable/4178442. 
Baker, Mark C. 1988. Incorporation: A theory of grammatical function changing. Chicago: Chicago University Press.

Bhatt, Rajesh \& Martin Walkow. 2013. Locating agreement in grammar: an argument from agreement in conjunctions. Natural Language \& Linguistic Theory 31(4). 951-1013. DOI 10.1007/s11049-0139203-y.

Bošković, Željko. 2009. Unifying first and last conjunct agreement. Natural Language \& Linguistic Theory 27(3). 455-496.

Good, Jeff \& Alan CL Yu. 2005. Morphosyntax of two Turkish subject pronominal paradigms. Clitic and affix combinations: Theoretical perspectives 74. 315-374.

Hankamer, Jorge. 2008. Ad-phrasal affixes and suspended affixation. In Chicago, IL: Paper presented at the LSA Annual Meeting.

Johnson, Kyle. 2006. Gapping. The Blackwell companion to syntax 1. 407-435.

Kabak, Bariş. Feb. 2007. Turkish suspended affixation. Linguistics 45. 311-347.

Kabak, Barış \& Irene Vogel. 2001. The Phonological Word and Stress Assignment in Turkish. Phonology 18(3). 315-360. DOI 10.1017/S0952675701004201.

Kahnemuyipour, Arsalan \& Jaklin Kornfilt. 2006. Declassifying Turkish "prestressing" suffixes. In Proceedings of the 2006 Annual Conference of the Canadian Linguistic Association.

Kamali, Beste. 2011. The question particle in Turkish: Consequences for the interfaces. Online complement to Proceedings of WCCFL 28.

Kamali, Beste \& Bridget Samuels. 2008. The syntax of Turkish pre-stressing suffixes. In 3rd Conference on Tone \& Intonation in Europe, Lisbon.

Kelepir, Meltem. 2001. Topics in Turkish syntax: Clausal structure and scope. MIT PhD thesis, pp. 2352.

Kornfilt, Jaklin. 1996. On Copular Clitic Forms in Turkish. ZAS Papers in Linguistics 6. 96-114.

Koylu, Yilmaz. 2018. A compositional approach to conjunct agreement in Turkish. Proceedings of the Linguistic Society of America 3(1). 17-1.

Kural, Murat. 1993. V-to (-I-to)-C in Turkish. UCLA occasional papers in linguistics 11. 17-54.

Marušič, Franc, Andrew Nevins, \& Amanda Saksida. 2007. Last-conjunct agreement in Slovenian. In Formal Approaches to Slavic Linguistics, pp. 210-227.

Ross, John Robert. 1967. Constraints on variables in syntax. MIT PhD thesis.

Sezer, Engin. 2002. Finite inflection in Turkish. The verb in Turkish 44. 1.

Zanon, Ksenia. 2014. On the Status of TP in Turkish. Studies in Polish Linguistics 9(3). 163-201.

İnce, Atakan. 2009. Dimensions of ellipsis: Investigations in Turkish. University of Maryland PhD thesis. 